\title{
Routine determination of urinary pregnanediol using a gas chromatograph with automatic sample application
}

\author{
D. A. PODMORE ${ }^{1}$ \\ From the Department of Chemical Pathology, \\ The Royal Infirmary, United Sheffield Hospitals, Sheffield
}

SYNOPSIS A method for the routine determination of urinary pregnanediol by gas-liquid chromatography is presented. By applying the samples automatically to the chromatograph overnight, batches of up to 25 samples can be easily handled. The method described is compared with that of Klopper, Michie, and Brown (1955).

The output of urinary pregnanediol in late pregnancy is being used increasingly as an index of placental activity. The method generally employed is that of Klopper, Michie, and Brown (1955); this is lengthy and includes two column chromatographic stages. The estimation of pregnanediol by gas chromatography after extraction of hydrolysed urine has been reported but this method has not lent itself to routine batch analysis in the past because of the need to apply specimens singly to the column at intervals. The development of a device for the automatic application of samples to the chromatogram now allows a batch of 25 samples and standards to be loaded into the apparatus and fed to the chromatograph automatically at pre-set intervals throughout the night (Podmore, 1965).

For comparison results are presented on 108 urine specimens determined by the method of Klopper et al. (1955), and the gas-liquid chromatographic method described.

\section{METHODS AND MATERIALS}

Analyses were performed by the gas-liquid chromatographic method described below on 24-hour samples of urine obtained chiefly from pregnant women. The pregnanediol output was also determined by the routine method of Klopper et al. (1955) modified in that hydrolysis, extraction, and centrifugation were carried out in large glass-stoppered test tubes. The final colour was measured using a Spekker absorptiometer with an Ilford 601 filter.

${ }^{1}$ Mr Podmore died on 2 December 1965. Requests for reprints should be addressed to Dr. A. Jordan, The Royal Infirmary, Sheffield, 6. Received for publication 28 June 1966.
GAS-LIQUID CHROMATOGRAPHIC METHOD To $5 \mathrm{ml}$. urine in a glass-stoppered test tube is added $0.75 \mathrm{ml}$. $10 \mathrm{~N}$ hydrochloric acid. After standing in a boiling water bath for $12 \mathrm{~min}$. the mixture is cooled and $5 \mathrm{ml}$. toluene added, the tube stoppered, mechanically shaken for $10 \mathrm{~min}$. and the layers allowed to separate, centrifuging if necessary. Three $\mathrm{ml}$. of the toluene layer is evaporated to dryness in a test tube by standing in a water-bath at 70 to $80^{\circ} \mathrm{C}$. and directing a current of nitrogen or air onto the surface. The use of a manifold with multiple nitrogen jets allows a whole batch to be evaporated simultaneously. The residue is dissolved in $1 \mathrm{ml}$. warm benzene, $1 \mathrm{ml}$. of acetyl chloride is added, and the mixture is allowed to stand for one hour at 20 to $25^{\circ} \mathrm{C}$. The tube is then replaced in the bath at $70^{\circ} \mathrm{C}$. and evaporated once more as described above. The dry residue is dissolved in $1 \mathrm{ml}$. benzene.

Fifty $\mu$ l. of each of the extracts are pipetted into small tinplate cylinders $(16 \times 4 \mathrm{~mm}$.) and the solvent allowed to evaporate. Standards containing pregnanediol in the range 1 to $5 \mu \mathrm{g}$. are provided by appropriate amounts of a pregnanediol diacetate solution in similar cylinders. A control standard, containing $4 \mu \mathrm{g}$. of pregnanediol, is run at intervals of 10 specimens so that a compensation can be made if any variation of response occurs over the run. The batch of sample cylinders is loaded into the automatic application device and argon connections are made. Electromagnetically, sample containers are fed to and removed from the flash heater of the chromatogram every 30 min.; a separate time switch stops the chart drive at the end of the run. The peaks are quantitated the following morning using peak height ; the measurement of peak area was found to be less convenient and no more accurate.

A Pye Argon chromatograph was used with a column loaded with $1 \%$ S.E. 30 on 100-120 mesh, acid-washed, siliconized Celite. The column was at $225^{\circ} \mathrm{C}$. and the flash heater $270^{\circ} \mathrm{C}$. The retention time of pregnanediol diacetate was 16 minutes. 


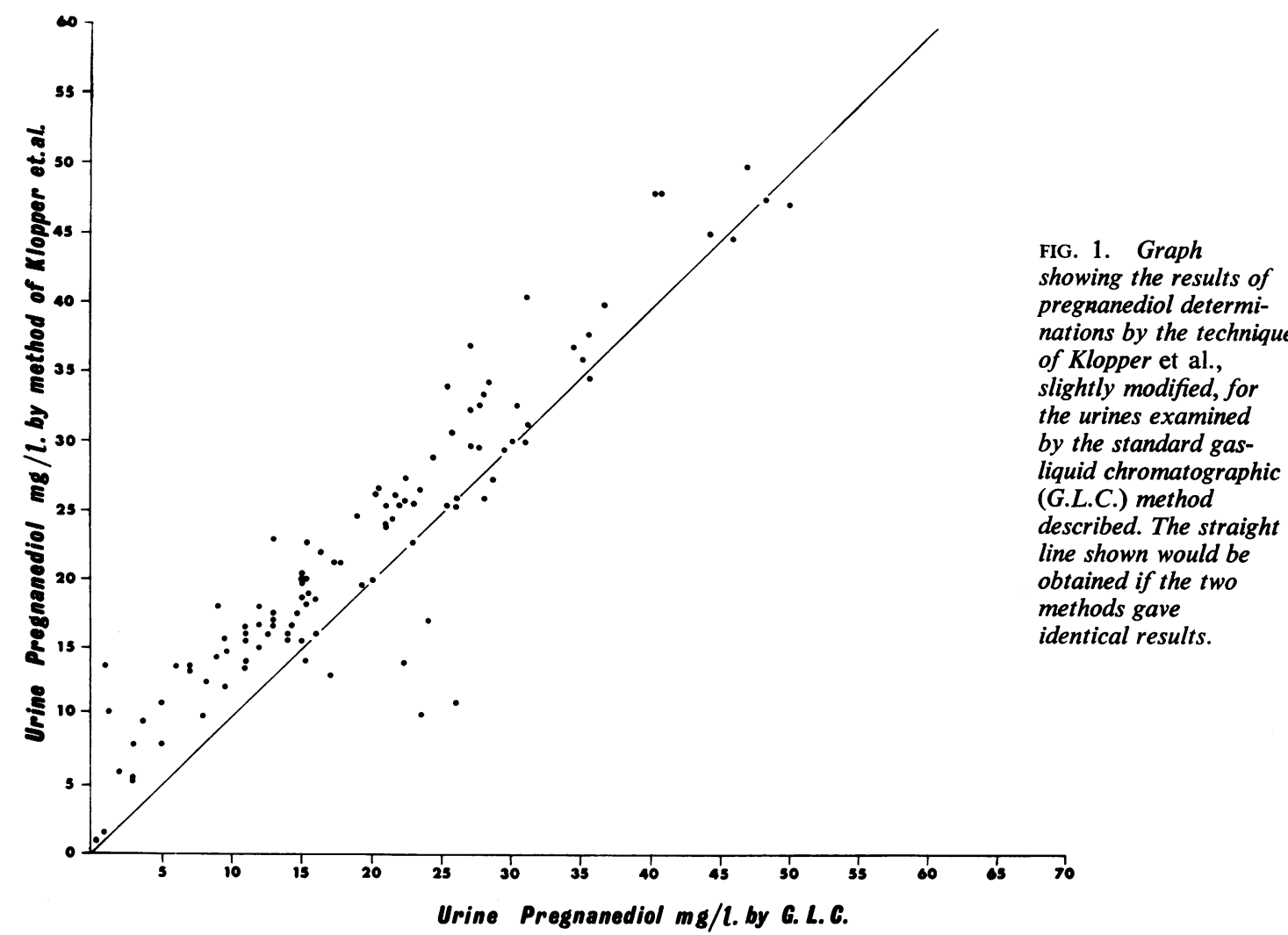

RESULTS

Using a direct toluene extract of acid-hydrolysed urine for gas-liquid chromatography, the pregnanediol peak was not well separated from other peaks in its vicinity. The standard gas-liquid chromatographic method described gave a well-separated peak: 98 to $104 \%$ of pregnanediol added to urine was recovered.

Some of the urines submitted over a period of three months for pregnanediol determination were determined both by the method of Klopper et al. (1955) and by the procedure described. These results on 108 urines are compared in Figure 1. It will be seen that there is a correlation between the two methods but that on the average the gas-liquid chromatographic method gives results some $3 \mathrm{mg}$./1. lower.

The method of Klopper et al. (1955) gave a standard deviation for the individual determination of $1.0 \mathrm{mg}$./1. and the standard gas-liquid chromatographic method gave $1.4 \mathrm{mg} . / 1$., calculated in each case from the duplicate results on 31 urine samples.

An attempt was made to ascertain how much of the pregnanediol was determined by the gas-liquid chromatographic technique. For this purpose the pregnanediol content of nine urines was determined in duplicate by the method of Klopper et al. (1955). The final colours were measured first in a Spekker absorptiometer using Ilford filter 601 (results shown in column 3 of Table I) and also in a spectrophotometer with readings at 400,425 , and $450 \mathrm{~m} \mu$ : the results of these readings after application of the Allen (1950) correction are shown in column 4. The nine urines were also estimated by gas-liquid chromatography, first by the described method (column 1) and secondly on a small aliquot of the final pure benzene extract from the Klopper method, that is to say, immediately before evaporation and the colour reaction (column 2).

The method of Klopper et al. (1955) (column 3) gives results higher than those given by the standard gas-liquid chromatography method (column 1). The difference averages about $3 \mathrm{mg}$. per litre. On the ground of specificity it seems reasonable to suppose that the values obtained by gas-liquid chromatography are more nearly the correct ones. The agree- 
TABLE I

PREGNANEDIOL LEVELS ESTIMATED ON NINE URINES BY VARIOUS METHODS ${ }^{1}$

\begin{tabular}{|c|c|c|c|c|}
\hline \multirow{2}{*}{$\begin{array}{l}\text { Urine } \\
\text { No. }\end{array}$} & \multicolumn{2}{|l|}{ Gas-Liquid Chromatography on } & \multicolumn{2}{|c|}{ Readings by the Method of Klopper et al. (1955) on } \\
\hline & $\begin{array}{l}\text { Acetylated Toluene Extract of } \\
\text { Hydrolysed Urine } \\
\text { (1) }\end{array}$ & $\begin{array}{l}\text { Final Benzene Solution by the } \\
\text { Method of Klopper et al. } \\
\text { (1955) } \\
\text { (2) }\end{array}$ & $\begin{array}{c}\text { Spekker Absorptiometer } \\
\text { (3) }\end{array}$ & $\begin{array}{l}\text { Spectrophotometer at } 400,425 \text {, } \\
\text { and } 450 \text { mu with Allen }(1950) \\
\text { Correction }\end{array}$ \\
\hline $\begin{array}{l}1 \\
2 \\
3 \\
4 \\
5 \\
6 \\
7 \\
8 \\
9 \\
\text { Mean } \\
\text { result }\end{array}$ & $\begin{array}{l}31 \\
10 \\
36 \\
21 \\
46 \\
22 \\
20 \\
47 \\
23 \\
\\
28 \cdot 4\end{array}$ & $\begin{array}{r}24 \\
8 \\
31 \\
17 \\
39 \\
18 \\
16 \\
30 \\
22 \\
\\
22.8\end{array}$ & $\begin{array}{l}32 \\
12 \\
40 \\
23 \\
50 \\
26 \\
25 \\
46 \\
29 \\
\\
31 \cdot 4\end{array}$ & $\begin{array}{l}27 \\
12 \\
34 \\
17 \\
37 \\
21 \\
17 \\
28 \\
26 \\
\\
24 \cdot 3\end{array}$ \\
\hline
\end{tabular}

${ }^{1}$ Results are expressed in $\mu \mathrm{g} . / 1$.

ment between the values obtained when the final benzene extract (immediately before evaporation and the colour reaction) is submitted to gas-liquid chromatography (column 2) and the Allen-corrected values (column 4) is quite reasonable: the differences are not significant $(P=0.44)$. That these results are lower than those given by the standard technique for gas-liquid chromatography (column 1) suggests that losses of the order of 15 to $20 \%$ occur in the bench method, but that the use of uncorrected readings with Ilford filter 601 results in an over-correction of these losses, presumably from background colour. The differences between columns 3 and 4 point to the magnitude of this background colour.

From a clinical point of view, although there may be variation in the estimates of pregnanediol output according to the method used, the significance of the value will be assessed from the range of normality found using that particular method.

\section{DISCUSSION}

The gas-liquid chromatographic method for preg- nanediol determination offers many advantages over the bench method. It requires considerably less time for the manipulations, smaller samples are used, and only $7 \mathrm{ml}$. of the solvent is required per estimation as against the method of Klopper et al. which requires some 100 to $120 \mathrm{ml}$. of redistilled solvents for each determination. The saving in cost is considerable, and the fire risk is reduced. In addition to pipettes, the only apparatus required to prepare the extract is two test tubes.

There is reason to believe that the results are closer to the truth.

I am indebted to Dr. G. Pennington and the staff of the Sheffield Regional Endocrine Centre who carried out the routine pregnanediol determinations and to Dr. A. Jordan for his help and discussion.

\section{REFERENCES}

Allen, W. M. (1950). J. clin. Endocr., 10, 71.

Klopper, A., Michie, E. A., and Brown, J. B. (1955). J. Endocr., 12, 209. Podmore, D. A. (1965). J. Chromat., 20, 131. 